\title{
A STUDY OF X-RAY PATTERN IN HIV PATIENTS IN RELATION TO CD4 COUNT
}

\author{
Sumita Mukherjee Basu Mullick¹, Sujit Kumar Bhattacharyya², Kumarjit Sinha³, Abhijit Mandal ${ }^{4}$ \\ 1 Professor and HOD, Department of Respiratory Medicine, Agartala Government Medical College and G. B. Panth Hospital, Agartala, \\ Tripura, India. \\ ${ }^{2}$ Associate Professor, Department of Respiratory Medicine, North Bengal Medical College, West Bengal, India. \\ ${ }_{3}^{3}$ Senior Registrar, Department of Respiratory Medicine, Agartala Government Medical College and G. B. Panth Hospital, Agartala, \\ Tripura, India. \\ ${ }^{4}$ Professor, Department of Respiratory Medicine, NRS Medical College, West Bengal, India.
}

\section{BACKGROUND}

ABSTRACT

HIV and Tuberculosis have close liaison from a long duration. Sometimes, it becomes very essential for early diagnosis of tuberculosis in patients with HIV. Simple x-ray chest often helps in the diagnosis of tuberculosis, especially in relation with variation of CD4 count.

Aim- To evaluate the extent and severity of illness from a simple x-ray of chest in patient with HIV.

\section{MATERIALS AND METHODS}

A descriptive study was conducted over 100 HIV patients in a tertiary care medical college hospital in Kolkata in West Bengal, India during the period from Jan 2015 to Jan 2016.

\section{RESULTS}

The studied group consisted predominantly of male patients and majority were from 30 - 50 years' age group. Patients with CD4 count less than $200 / \mathrm{cc}$ were having abnormal radiology in all patients (100\%) as compared to patients having above $200 / \mathrm{cc}$ CD4 count, where radiological abnormalities were found in 53.3\%. Pulmonary infiltrate was predominant in both the groups below and above $200 /$ cc CD 4 count (20\% vs. $27 \%$ ). Extrapulmonary radiological features were more in high CD4 count group (10\% vs. 5\%).

\section{CONCLUSION}

In patients with lower CD4 count, radiological abnormalities were more compared to patients with higher CD4 count. Pulmonary infiltrate is more in both the groups and extrapulmonary radiological abnormalities were slightly more in higher CD4 count group.

\section{KEY WORDS}

CD4, HIV/AIDS, Tuberculosis.

HOW TO CITE THIS ARTICLE: Mullick SMB, Bhattacharyya SK, Sinha K, et al. A study of x-ray pattern in HIV patients in relation to CD4 count. J. Evolution Med. Dent. Sci. 2018;7(23):2819-2822, DOI: 10.14260/jemds/2018/636

\section{BACKGROUND}

With the advent of medical science, HIV has become a threat in our society. Tuberculosis has close bond with HIV. Dual action of these two horrifying health situations make it more worse. In ancient history of diseases when tuberculosis remained a horror due to non-discovery of proper antitubercular drugs (ATD), later though the picture changed. Now even though there are plenty of anti-tubercular drugs, but with the advent of Human Immunodeficiency Virus (HIV) infection situations become dreaded when tuberculosis again flare up in a new strain, especially in the form of Multidrug Resistant Tuberculosis (MDR-TB).

HIV infection is a potent risk factor for tuberculosis, either by activation of latent tuberculosis or by undermining the cell mediated immunity through depletion of CD4 lymphocytes. ${ }^{1}$ In March 2017, the Government of India (GOI) announced the elimination of Tuberculosis by 2025. India accounts for about a quarter of global Tuberculosis burden.

'Financial or Other Competing Interest': None.

Submission 22-04-2018, Peer Review 22-05-2018,

Acceptance 28-05-2018, Published 04-06-2018.

Corresponding Author:

Sujit Kumar Bhattacharyya,

Vill Aminpur, PO. Khamarchandi,

PS, Haripal District, Hooghly-712405,

West Bengal, India.

E-mail: drsujit.haripal@yahoo.in

DOI: $10.14260 /$ jemds $/ 2018 / 636$

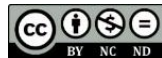

Worldwide, India is the country with the highest burden of TB and MDR-TB. There are an estimated 79,000 MDR-TB patients among the notified cases of pulmonary tuberculosis each year. India is also the country with second highest number after South Africa of estimated HIV associated Tuberculosis cases. In 2016 an estimated 28 lakhs cases occurred and 4.5 lakhs people died due to Tuberculosis cases. ${ }^{2}$ CD 4 count implies the degree of immune suppression in HIV infected patients. Immunosuppression results in lack of ability of the body to fight infections leading to increased susceptibility of various types of diseases. Lung is one of the susceptible organs. So, $\mathrm{x}$-ray chest radiographs have immense diagnostic importance in HIV patients. ${ }^{3}$ India is home to approximately 2.5 million people living with HIV, the largest number of cases of any country in the world and is recognised as the source of increasing HIV prevalence among its South-Asian neighbours. Recently released National HIV prevalence estimates for India indicate that $0.22 \%$ of women and $0.36 \%$ men aged 15 - 49 years are infected. ${ }^{4}$ Over $70 \%$ of HIV infected persons have one or more respiratory illnesses during the course of their HIV diseases. Pulmonary complications are commonly seen among CD4 count decline less than 200/cc. Most of them are due to opportunistic pathogens common in HIV. Chest radiographs are the corner stone of diagnostic evaluations of respiratory symptoms in HIV infected patients. Currently, incidence of tuberculosis is declining by about $1-2 \%$ per year and achieve the TB 
elimination goal by 2025 . We need to have a decline in TB incidence by about $15-20 \%$ annually. $^{5}$

\section{Objective}

Objective of this study was to evaluate the extent and severity of illness from a simple x-ray chest in patients with HIV.

\section{MATERIALS AND METHODS}

The study was conducted in NRS Medical College, a Government Hospital in Kolkata, West Bengal, India. Over 100 HIV patients were included in our study during the period from Jan 2015 to Jan 2016. It was a descriptive study. Data including chest radiograph, sputum for AFB, CD4, CBNAAT study were confidentially collected from all HIV patients who are under study. Written consent from all patients who were included in our study were taken. All patients above the age of 18 years with confirmed HIV infection as per NACO guidelines were the subjects of the study. The chest radiographs were blindly reported by two radiologists who were not aware about the study. Ultimately, data was divided according to the CD4 count above 200/cc and below 200/cc.

\section{RESULTS}

100 patients were included in our study, of which 70 were male and 30 were female. Distribution of age varied between 19 - 70 years with mean age of 34.5 years (Table 1 and 2). Most of them were from lower socioeconomic status as evidenced from their professions. Manual labourers and driver in combination contribute 35\%, hawkers $25 \%, 30 \%$ were victims of their sexual partners notably wife, $5 \%$ were accidental victims of blood transfusion (Table 3). $60 \%$ cases were put on ATD on the basis of Radiology, CBNAAT and AFB smear study. 20 cases (20\%) were smear positive pulmonary tuberculosis, while $80 \%$ were smear negative. CBNAAT study revealed detection of $\mathrm{AFB}$, but rifampicin was sensitive in 5 (5\%) cases and was resistant in $5(5 \%)$ cases. By stratification of CD4 T-Lymphocyte 75 (75\%) patients were above 200 /cc and 25 patients (25\%) were less than 200/cc. Asymptomatic patients accidentally diagnosed for other causes were found in 20 cases (20\%) and rest $80 \%$ were symptomatic with predominantly loss of weight, fever, cough or weakness. Rare symptoms were ascites, pain abdomen, lymphadenopathy or haemoptysis (Table 4). Study group was divided into two according to radiological abnormalities on $\mathrm{x}$ rays seen in the group above and below 200/cc CD4 count. 25 cases were included under 200/cc CD4 group and all (100\%) had radiological abnormalities, which were pulmonary infiltrates in 20 cases (80\%) with equal frequency (1: 1) in both upper and lower zones and preferably on right side followed by bilateral hilar adenopathy in 5 cases (20\%). 75 cases were included in the group, where CD4 count were above 200/cc. Out of which 35 cases were found to have no radiological abnormalities, whereas 40 cases $(53.3 \%)$ out of 75 had radiological abnormalities. Pulmonary infiltrates were the most common presentation in this group, where it was predominant mostly in upper zone in 17 cases followed by lower zone in 10 cases and preferably on right side. Other radiological abnormalities that were found in these categories were hilar adenopathy 4 (5.3\%), pleural effusion 6
(8\%) and miliary mottling in 3 cases (4\%). Extrapulmonary manifestation were found more in the above CD4 count group as compared to low CD4 count in the ratio of 2: 1 (Table 5).

\begin{tabular}{|c|c|c|}
\hline Age Distribution (Years) & Number & Percent \% \\
\hline$<30$ & 45 & 45 \\
\hline $30-50$ & 50 & 50 \\
\hline$>50-70$ & 5 & 5 \\
\hline \multicolumn{2}{|c|}{ Table 1. $\mathbf{N = 1 0 0}$} \\
\hline Sex & \% \\
\hline Male & 70 \\
\hline Female & 30 \\
\hline \multicolumn{2}{|c|}{ Table 2. $\mathbf{N = 1 0 0}$} \\
\hline
\end{tabular}

\begin{tabular}{|c|c|c|}
\hline Professions & Number & Percent \\
\hline Driver & 15 & 15 \\
\hline Students & 5 & 5 \\
\hline Victim & 30 & 30 \\
\hline Labourer & 20 & 20 \\
\hline Businessman & 25 & 25 \\
\hline Accidental Table 3. N= 100 \\
\hline \multicolumn{2}{|c}{} \\
\hline \multicolumn{2}{|c|}{}
\end{tabular}

\begin{tabular}{|c|c|}
\hline Asymptomatic & 20 cases \\
\hline Symptomatic & 80 cases \\
\hline Respiratory distress & 10 \\
\hline Fever & 50 \\
\hline Ascites & 5 \\
\hline Pain abdomen & 5 \\
\hline Lymphadenopathy & 5 \\
\hline Cough & 45 \\
\hline Weakness & 30 \\
\hline Loss of weight & 60 \\
\hline Haemoptysis & 10 \\
\hline \multicolumn{2}{|c|}{ Table 4. $\mathbf{N =} \mathbf{1 0 0}$} \\
\hline
\end{tabular}

\begin{tabular}{|c|c|c|c|c|c|c|}
\hline $\begin{array}{c}\text { CD4 } \\
\text { Count }\end{array}$ & $\begin{array}{l}\text { Total } \\
\text { Cases }\end{array}$ & & Total & Right & Left & Both \\
\hline \multirow[t]{3}{*}{$\begin{array}{c}<200 \\
/ \mathrm{cc} \\
\end{array}$} & 25 & Bilateral hilar & 5 & & & \\
\hline & & $\begin{array}{c}\text { Pulmonary } \\
\text { infiltrate, upper } \\
\text { zone }\end{array}$ & 10 & 6 & 2 & 2 \\
\hline & & $\begin{array}{c}\text { Pulmonary } \\
\text { infiltrate, lower } \\
\text { zone }\end{array}$ & 10 & 4 & 3 & 3 \\
\hline \multirow[t]{6}{*}{$>200 / \mathrm{cc}$} & 75 & $\begin{array}{c}\text { Pulmonary } \\
\text { infiltrate, upper } \\
\text { zone }\end{array}$ & 17 & 9 & 6 & 2 \\
\hline & & Lower zone & 10 & 5 & 3 & 2 \\
\hline & & Hilar & 4 & 1 & 3 & \\
\hline & & Pleural effusion & 6 & 2 & 4 & \\
\hline & & Miliary shadow & 3 & & & \\
\hline & & Normal & 35 & & & \\
\hline
\end{tabular}

\section{DISCUSSION}

Association of HIV with tuberculosis is having probably the strongest bond. With increase in prevalence of HIV in India, physicians must be aware about their co-existence with tuberculosis. Simple x-ray chest often help in diagnosis of tuberculosis. In our study, we mainly focus on different radiographic presentation in HIV patients in relation with CD4 count. Our study was descriptive. All HIV patients with 
radiological presentation either with past history of tuberculosis or not were included in our study. Mean age in our study group was 34.5 years and male: female ratio was 4:1 and majority belong to lower socioeconomic group. Similar observation was found in the study by Sircar AR and associates, where mean age in their study was $34.9 \pm 12$ years and ratio of male: female was 3: 1 and majority (80\%) were from lower socioeconomic group. ${ }^{6}$ Mahesha Padyana in his study observed predominant female and mean age amongst male was 37.4 years and female was 35.3 years respectively and majority were from unskilled work group. In our study, commonest radiological presentation was parenchymal opacities followed by hilar adenopathy and pleural effusion and miliary tuberculosis. Normal radiography was seen in $40 \%$ cases. However, we did not find any cavity in our study, where Tripathy $S$ et al found much cavitation that was related to higher CD4 counts. ${ }^{7}$ Similar observation was found by Perlman DC and associates. ${ }^{8}$ Banafsheh Moradmand Badie observed less cavity in HIV positive cases, similar to our observation. ${ }^{9}$ We found extrapulmonary presentation more in higher CD4 count as compared to lower CD4 count (10\% vs. $5 \%$ ). Pozniak AL and his associates observed extrapulmonary tuberculosis was not associated with decreased CD 4 count. ${ }^{10}$ In contrary, Akinbami $\mathrm{AA}$ and his colleague did not find any correlation in $\mathrm{x}$-ray with CD4 count variation. ${ }^{11}$ About three-quarters of HIV infected patients had normal chest $\mathrm{x}$-ray, despite the CD4 count remained low. However, Keiper et al observed lung infiltration and consolidation in 69\% cases. Bilaterally, $68.5 \%$ of mid and lower zone or all zone involvement were more commonly seen. ${ }^{12}$ Comparing with our study where there was no predilection of zonal distribution, especially where CD4 count was less than 200 Christopher Affusium et al found pulmonary nodules more in the upper, mid and lower zone. ${ }^{13}$ Keiper et al observed more unilateral apical opacity. ${ }^{12}$ In our study, pulmonary infiltrate was more common on right side. Similar observation was found in some studies. Some study observed it was more on left side. ${ }^{13}$ Gold JA observed more nodular lesion and adenopathy with CD4 count less than $200 /$ cc. $^{14}$

Vijayesh K Tiwari observed miliary shadow and pleural effusions were more in patient with CD4 count more than $200 /$ cc. $^{15}$ Similar observation was seen in our study, where miliary shadow and pleural effusion were found in patients with high CD4 count. Similar observations were found in some study. ${ }^{3,8}$ However, $\mathrm{N}$ Ravi et al observed pleural effusion and lymphadenopathy were more common in low CD4 count. ${ }^{16}$ Incidence of HIV in female accounts for rising percentage of all HIV cases with husband's risk behaviour described as major source of infection. ${ }^{17}$ In our study $30 \%$ patients were victims of sexual diseases from their sexual partners, notably husband. Blood transfusion was a risk factor in $5 \%$, closer to some study where it was $12.1 \%{ }^{6}$

\section{CONCLUSION}

HIV and tuberculosis have close relation in the newer clinical practice. High degree of clinical suspicion is essential, and presence of the second should be suspected if any one comes across first. Simple x-ray chest often helps in diagnosis of tuberculosis. In our study, radiological abnormalities were found much more fequently in patients with lower CD4 count. Pulmonary infiltrates were found more in both higher and lower CD4 group, but extrapulmonary radiological abnormalities were found more in higher CD4 group.

\section{ACKNOWLEDGEMENT}

Thanks Mr. Santosh Shaw for helping in completing this manuscript.

\section{REFERENCES}

[1] UNAIDS. Report on the global AIDS epidemic: executive summary. UNAIDS/6-20E, 2006.

[2] Global TB report 2017. WHO 2017.

[3] Padyana M, Bhat RV, Dinesha $M$, et al. HIVTuberculosis: A Study of Chest X-Ray Patterns in Relation to CD4 Count. N Am J Med Sci 2012;4(5):2215.

[4] Summary of findings of the $3^{\text {rd }}$ National family health survey. India NFHS-3 International Institute for Population Science And Macro Inter Inc 2005-6. (First assessed on December 2004).

[5] India TB report 2018 revised National TB control programme annual status report. www.tbcindia.gov.in

[6] Sircar AR, Tripathi AK, Choudhary SK, et al. Clinical profile of AIDS: a study at a referral hospital. J Assoc Physicians India 1998;46(9):775-8.

[7] Tripathy S, Menon P, Joshi DR, et al. Preliminary observation on lymphocyte subpopulation in HIV seropositive and HIV seronegative tuberculosis patients in Pune, India. Indian J Med Res 2000;111:195-8.

[8] Perlman DC, el-Sadr WM, Nelson ET, et al. Variation of chest radiographic patterns in pulmonary tuberculosis by degree of human immunodeficiency virus related immunosuppresion. The Terry Beirn community programs for clinical research on AIDS (CPCRA). The AIDS clinical trials group (ACTG). Clin infect Dis 1997;25(2):242-6.

[9] Banafsheh MB, Mehran M, Mehran I, et al. Comparing radiological features of pulmonary tuberculosis with and without HIV infection. Journal of AIDS and Clinical Research 2012;3:188.

[10] Pozniak AL, MacLeod GA, Ndiovu D, et al. Clinical and chest radiographic features of tuberculosis associated with human immunodeficiency virus in Zimbabwe. Am J Respir Crit Care Med 1995;152(5 Pt 1):1558-61.

[11] Akinbami AA, Adegboyega AO, Oshinaike 00, et al. Chest $\mathrm{X}$ - ray findings in HIV patients in relation to the CD4 count. Nig Q J Hosp Med 2011;21(4):306-11.

[12] Keiper MD, Beumont M, Elashami A, et al. CD4 T lymphocyte and the radiographic presentation of pulmonary tuberculosis. A study of the relationship between these factors in patient with Human Immunodeficiency Virus infection. Chest 1995;107(1):74-80.

[13] Christopher A, Vivien A, Emeka BK, et al. The effect of low CD4+ lymphocyte count on the radiographic patterns of HIV patients with pulmonary tuberculosis among Nigerians. Tuberculosis Research and Treatment 2013;2013:1-4.

[14] Gold JA, Rom WN, Harkin TJ. Significance of abnormal chest radiograph findings in patients with HIV1 infection without respiratory symptoms. Chest 2002;12(5):1472-7. 


\section{Jemds.com}

[15] Vijayesh KT, Sanjay B, Abhishek K, et al. Pattern of pulmonary tuberculosis in HIV positive patients. Int J Adv Int Med Sci 2016;1(2):46-8.

[16] Ravi N, Nagaraj BR, Bagath KS, et al. A study of various chest radiological manifestations of pulmonary tuberculosis in both human immunodeficiency virus positive and human immunodeficiency virus negative patients in south Indian population. West African Journal of Radiology 2017;24(1):14-9.

\section{Original Research Article}

[17] Silverman JG, Decker MR, Saggurti N, et al. Intimate partner violence and HIV infection among married Indian women. JAMA 2008;300(6):703-10. 